\title{
Performance and Analysis of Wide Band Micro-strip Six- Port Junctions for Cognitive Radio
}

\author{
S.Siva sundara pandian, C.D.Suriyakala \\ Sathyabama University \\ Chennai-600 119, India
}

\begin{abstract}
This paper presents about the wide band six-port junctions based on micro-strip technology for c band (4 to $8 \mathrm{Ghz}$ ), $\mathrm{Ku}$ band(12 to $18 \mathrm{GHz}$ ), K band(18 to $26.5 \mathrm{GHz}$ ), $\mathrm{Ka}$ band(26.5 to $40 \mathrm{GHz}), \mathrm{V}$ band $(50$ to $75 \mathrm{GHz})$ is proposed and their performance was analyzed. A six-port junction consists of one Wilkinson power divider and three $-3 \mathrm{~dB}$ hybrid couplers or two hybrid couplers and two power dividers. The six-port junctions presented here are designed at the center frequency of $5.8 \mathrm{GHz}, 10 \mathrm{GHz}, 37 \mathrm{GHz}$ and $73 \mathrm{GHz}$. The circuit is simple structure, small size, and low cost, good performance. We employed Advanced Design System (ADS) for simulation. The two input ports connected with local oscillator signal and RF signal, respectively. The I and Q signals are composed by two of the four output signals. With this simple structure, small size, low cost and good performance, wide band microstrip six-port junction can be used for cognitive radio. Saving mixer, I/Q signals can be obtained through direct demodulation.
\end{abstract}

\section{Keywords}

hybrid coupler; micro-strip; power divider; six-port junction;

\section{INTRODUCTION}

Today there is no freely available spectrum for future generation. Around $2.5 \mathrm{GHz}$ the spectrum is completely occupied. So by using the cognitive radio the spectrum can be efficiently utilized. A Cognitive Radio is a radio that can easily identify freely available spectrum and autonomously change its transmission parameters based on the interaction with the complex environment (radio scene, application and user requirements) in which it operates. The spectrum can be efficiently utilized by using the cognitive radio. Since the cognitive radio is always looking for freely available spectrum it needs a wide band receiver and wide band antenna for spectrum sensing. So by using the six port junction the receiver can be used as a wide band receiver.

Today there are two major issues in wireless communication receivers in order to meet the increasing demand for high data rates. One is cost should be brought down and another one is the receivers should be wideband receivers. The wireless communication system should be small sized and low cost device structure. The filters can be implemented for heterodyne receivers for RF and IF using surface acoustic wave or crystal filters and hence the size and cost will be more. So the researchers are focusing their effort towards the direct conversion receivers. The direct conversion receiver is also called as homodyne receivers which has no IF amplifier, IF band-pass filter or IF local oscillator. If we implement direct conversion receivers, there are many problems to be solved for analog impairments. Even though there are number of receiver architectures are sought after, one of the promising architecture is the six-port There are number of advantages in direct receivers like it is simpler and less costly ,no IF amplifier, IF band-pass filter or IF local oscillator required for final down conversion and no image frequency. In recent years there was more interest in six port technology due to its advantages and applications. Several six port circuits with various methods have been designed and analyzed.

The six port junction effectively reduces the occupied area to $25 \%$ of the conventional six port junction due to open loaded stubs [1]. A single layer elliptic coupler was used to design six port junctions to get wide bandwidth [2]. A new six port junction based on micro strip technology was simulated and implemented for $10 \mathrm{GHz}$ which consists of two hybrid couplers and two power dividers [3]. The another six port junction which has three hybrid couplers and one power divider was implemented in a multilayered meandered manner and the size reduction is about $78 \%$ compared to planar design[4]. In [5-9] a wideband direct conversion receiver with heterodyne architecture have been presented. Two types of tunable receiver architectures are presented and analyzed. One structure is based on a tunable band pass filter, and a second system is based on a varactor-based tunable six-port demodulator, with the latter showing better sensitivity and dynamic range[10]. The RF front-end platform makes use of a silicon varactor-tuned band pass filter in connection with a tunable six-port demodulator. Varactor diodes of both of the tunable structures are independently biased using two different sets of supply voltage[11].

In this paper the wide band six-port junctions based on micro-strip technology for $\mathrm{c}$ band (4 to 8Ghz), Ku band (12 to $18 \mathrm{GHz}), \mathrm{K}$ band(18 to $26.5 \mathrm{GHz}), \mathrm{Ka}$ band(26.5 to 40 $\mathrm{GHz}), \mathrm{V}$ band $(50$ to $75 \mathrm{GHz})$ is proposed and their performance was analyzed. Section two describes about the formation of ultra wide band six port junction using two hybrid couplers and one power divider and also about design of hybrid coupler and power divider. Section three describes our investigation of ultra wide band six port junction simulation using ADS software and analyzed about the reflection coefficient and transmission coefficient and phase difference. Section four concludes our work.

\section{SIX-PORT JUNCTION DESIGN}

To measure complex reflection coefficient, the six-port was found to be a very good one of a microwave device. The six port junction consists of two input ports and four output ports as shown in Fig.1. The six-port describes a linear device with two inputs,. the incoming RF-signal and the LO, and with four outputs connected to nonlinear devices with a square-law characteristics which are called power detectors . Usually diodes are employed. Actually, such a six-port device with four diodes is nothing else but a four-arm receiver employing the so called additive mixing i.e., a superposition of the RFsignal and the LO followed by a square-law processing. Several unwanted signal components can be removed after low-pass filtering. 
Actually a six port junction is a five port device in communication circuits. Because the output consists of the Icomponent and the Q-component of the signal, plus a component called the rectified wave and the input signals are RF signal and local oscillator signal. Hence, it is sufficient to have three output signals to separate these three output components. The six-port junctions presented here are designed at the center frequency of $5.8 \mathrm{GHz}, 10 \mathrm{GHz}, 37 \mathrm{GHz}$ and $73 \mathrm{GHz}$. One simulated six port junction consists of one Wilkinson power divider and three $90^{\circ}-3 \mathrm{~dB}$ hybrid couplers. The block diagram of the proposed six-port junction is shown in Fig.1.The Ports 1 is connected to a local oscillator and port 2 is connected to received RF signals. The other four ports port3, port4, port5 and port6, are connected to power detectors. By applying a suitable Algorithm, magnitude and phase of the unknown microwave signal can be determined from the signal levels or readings of the four combined signals for any given modulation scheme. The six-port junction is simulated using Advanced Design System (ADS). The power dividers and hybrid couplers are designed respectively. Combining them, a six-port junction has been constructed. In this paper the six-port junction is designed and simulated for S- parameters of reflection coefficient S11,S22 and transmission coefficients S13,S14,S15,S16 S23,S24,S25,S26 and phase difference between input and output ports S13,S14,S15,S16 S23,S24,S25,S26. The S- parameters S11 and S22 should be minimum and it should be lower than -20 $\mathrm{dB}$ at the center frequency. The isolation $\mathrm{S} 12$ of ports 1 and 2 should be maximum. The transmission coefficients should be close to the theoretical value $-6 \mathrm{~dB}$. The phase shift between the two input ports (ports 1 and 2) and the phase differences between ports 3 and 5 as well as ports 4 and 6 should be close to $90^{\circ}$.

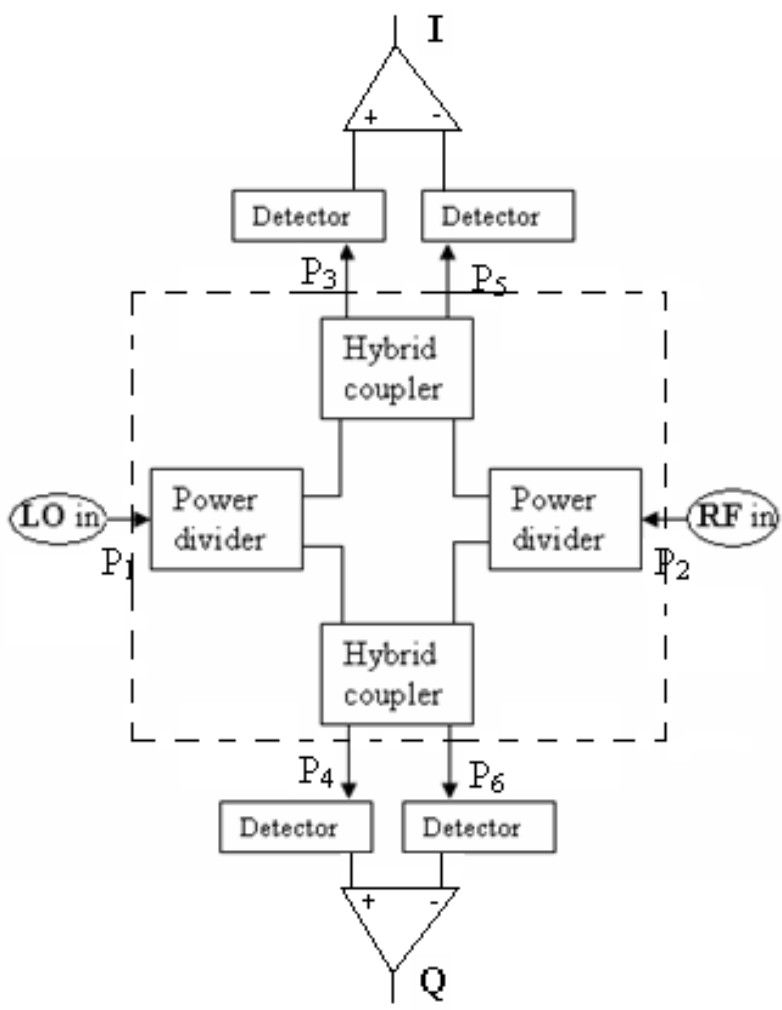

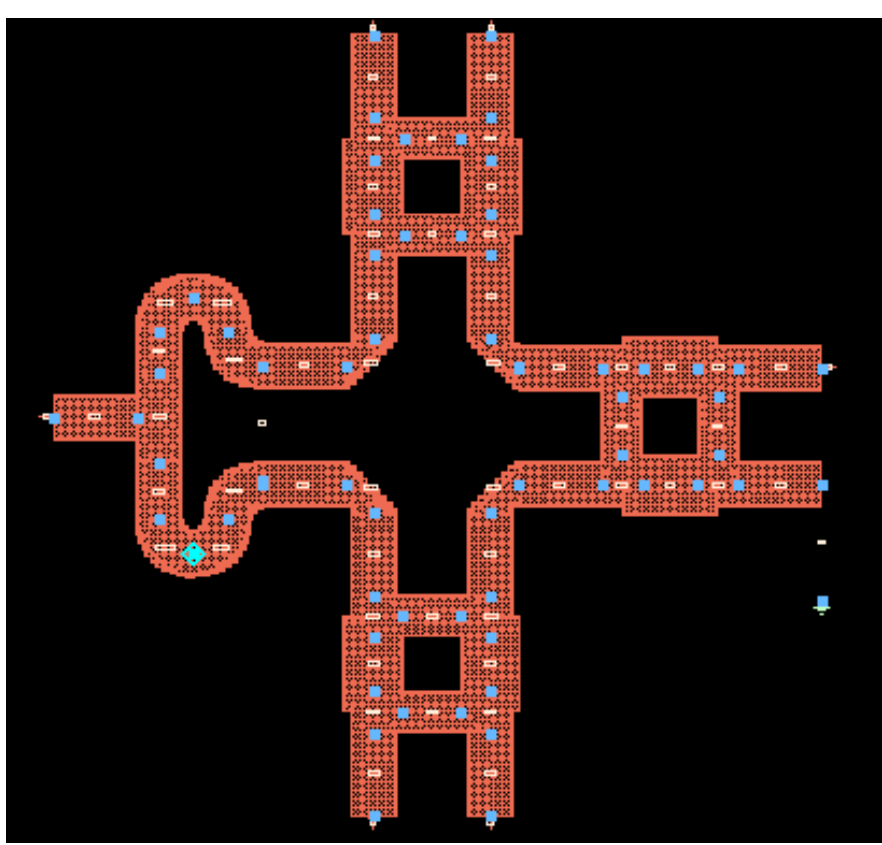

Fig.2: proposed six port junction layout

\section{A. Power Divider}

The power divider is optimized with two goals: to minimize S11 and to keep S21 and S31 close to $-3 \mathrm{~dB}$. The simulation diagram of the proposed Wilkinson power divider is shown in Fig.2. The micro-strip structure with substrate thickness1.6mm , relative dielectric constant $\mathrm{\varepsilon r}=4.5$ and Conductor thickness $0.035 \mathrm{~mm}$ is used in this design for $5.8 \mathrm{Ghz}$. With tool Line Calc in ADS, the effective width and length of micro-strip line are calculated. The micro-strip structure with substrate thickness $0.5 \mathrm{~mm}$, relative dielectric constant $\varepsilon \mathrm{r}=2.55$ and Conductor thickness $0.03 \mathrm{~mm}$ is used in this design for $10 \mathrm{Ghz}$ and for $37 \mathrm{GHz} \varepsilon \mathrm{r}=8.6$,substrate thickness is $270 \mathrm{um}$. The lumped element Wilkinson power splitter exhibits perfect isolation at the input port and equal power division at the output ports. These can be seen from s11, s21 and s31 plots in Figure 5, obtained via ADS tool. At $73 \mathrm{GHz}, \mathrm{s} 11$ drops down to $-38 \mathrm{~dB}$, when simulated with ideal elements. Likewise, s21 and s31 values are $-3 \mathrm{~dB}$ as expected, indicating that the A classical microstrip Wilkinson power splitter consists of two quarter wave microstrip line segments with characteristic impedance $\mathrm{Zo} \sqrt{2}$ the operating canter at frequency fo and a $2 \mathrm{Zo}$ lumped resistor connected between the two ports, as shown in Figure3. The lumped element Wilkinson power splitter exhibits perfect isolation at the input port and equal power division at the output ports. These can be seen from S11, S 21 and S31 plots in Figure 5, obtained via ADS tool. At $73 \mathrm{GHz}, \mathrm{S} 11$ drops down to $-38 \mathrm{~dB}$, when simulated with ideal elements. Likewise, S21 and S31 values are $-3 \mathrm{~dB}$ as expected, indicating that the power is equally. divided into two at the center frequencies. However, it should be noted that a Wilkinson divider/combiner is not a broadband device. Typical frequency bandwidths do not exceed $20 \%$ of the center frequency. 


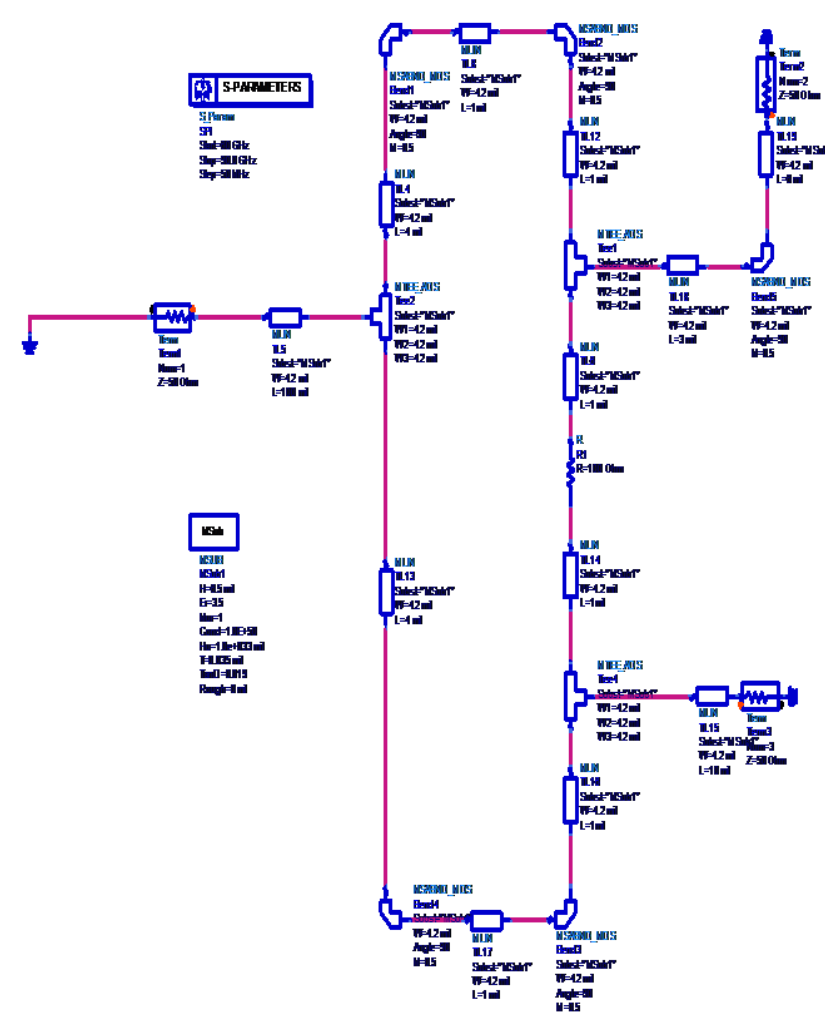

Fig.3: Power divider

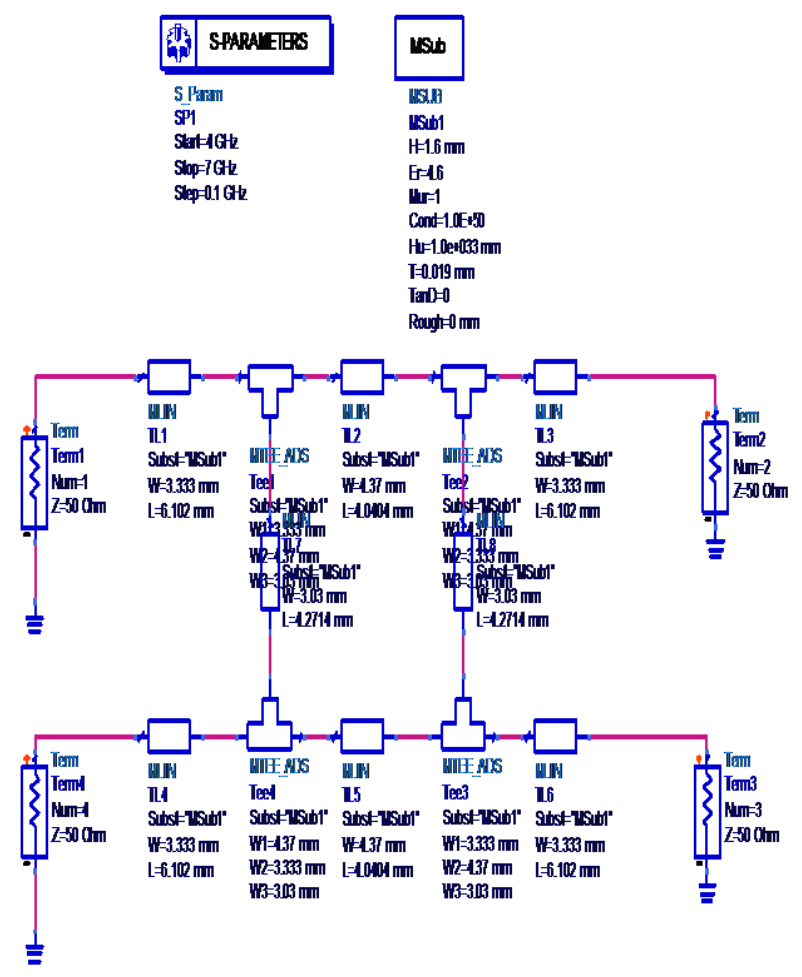

\section{B. Hybrid Coupler}

There are two types of hybrid couplers based on the phase difference. They are 90 degree and 180 degree hybrid couplers. A signal applied to port 1 splits equally between ports 2 and 3 with one of the outputs exhibiting a relative $90^{\circ}$ phase shift. If ports 2 and 3 are properly terminated into matching impedances, nearly all the signal applied to port 1 is transmitted to the loads connected to ports 2 and 3 . In this circumstance, port 4 receives negligible power and is termed isolated. However, if there is an impedance mismatch at port 2 , for example, then signal power reflected back from port 2 were divided proportionally between ports 1 and 4 . Power is not fed to port 3. The $73 \mathrm{GHz}$ hybrid coupler has been designed as shown in Fig.4. The dimension of input lines is $4.2 \mathrm{mil}$ for the width and 40mil for the length For the main line, the dimension is $4.2 \mathrm{mil}$ for the width and $45 \mathrm{mil}$ for the length. While for the shunt arms is $4.2 \mathrm{mil}$ for the width and $35 \mathrm{mil}$ for the length. The main difference between low and high frequency is by looking at the length line of the hybrid coupler. This is because the length is inversely proportional to width of the frequency. The hybrid coupler is optimized with two goals: to minimize S11 and S41 (lower than -20dB), and to keep S21 and $\mathrm{S} 31$ close to $-3 \mathrm{~dB}$. The hybrid coupler is optimized with two goals: to minimize S11 and S41 (lower than $-20 \mathrm{~dB}$ ), and to keep S21 and S31 close to $-3 \mathrm{~dB}$.

\section{RESULTS AND DISCUSSION}

The six-port junction circuit is simulated with the frequency of $5.8 \mathrm{GHz}, 10 \mathrm{GHz}, 30 \mathrm{GHz}, 37 \mathrm{GHz}$ and $73 \mathrm{GHz}$. Fig. 5 shows simulated results for $\mathrm{S} 11, \mathrm{~S} 22$ and $\mathrm{S} 12$ for a) $5.8 \mathrm{GHz}$ b) $10 \mathrm{GHz}$ c) $30 \mathrm{GHz}$ d) $37 \mathrm{GHz}$ e) $73 \mathrm{GHz}$ for the proposed six-port junctions. It can be noted that the return loss of these two ports is lower than $-20 \mathrm{~dB}$ at the center frequency $5.8 \mathrm{GHz}, 10 \mathrm{GHz}$ , $30 \mathrm{GHz} 37 \mathrm{GHz}$ and $73 \mathrm{GHz}$. Fig.6(a,b,c,d) presents simulated results of phase port 2 to output ports S13, S14, S15 and S16 for a) $5.8 \mathrm{GHz}$ b) $10 \mathrm{GHz}$ c) $30 \mathrm{GHz}$ d) $37 \mathrm{GHz}$ e) $73 \mathrm{GHz}$. Fig.7 shows simulated S31 - S61 (representing the transmission coefficients of port 1 to the output ports) of the proposed sixport junction. It is found that the simulated results for the transmission coefficients are close to the theoretical predicted value $-6 \mathrm{~dB}$ over the operating frequency band for $5.8 \mathrm{GHz}$ and $10 \mathrm{GHz}$. But for $30 \mathrm{GHz}, 37 \mathrm{GHz}$ and $73 \mathrm{GHz}$ the transmission coefficient is slightly greater than $-6 \mathrm{~dB}$. So microstrip line has good performance for less than $10 \mathrm{GHz}$. The average phase difference of the adjoining output ports over the operating frequency band is close to the theoretical value of $90^{\circ}$. For $5.8 \mathrm{GHz}$ the reflection coefficients $\mathrm{S} 11, \mathrm{~S} 22$ are lower than $22.16 \mathrm{~dB}$ and the isolation between RF port and LO port S12, is lower than $-26.045 \mathrm{~dB}$ at center frequency $5.8 \mathrm{GHz}$. The average phase difference of the adjoining output ports over the operating frequency band is close to the theoretical value of $90^{\circ}$. For $37 \mathrm{GHz}$ the reflection coefficients S11, S22 are lower than $-25.44 \mathrm{~dB}$ and the isolation between RF port and LO port $\mathrm{S} 12$, is lower than $-12.623 \mathrm{~dB}$ at center frequency $37 \mathrm{GHz}$ The transmission coefficients are close to $-8 \mathrm{~dB}$ hybrid and monolithic Microstrip six-port circuits. Compared to SIW structure, Microstrip structure can achieve higher Q value. It is shown through simulations and measurements offer a great flexibility in system configuration, reduction in system 


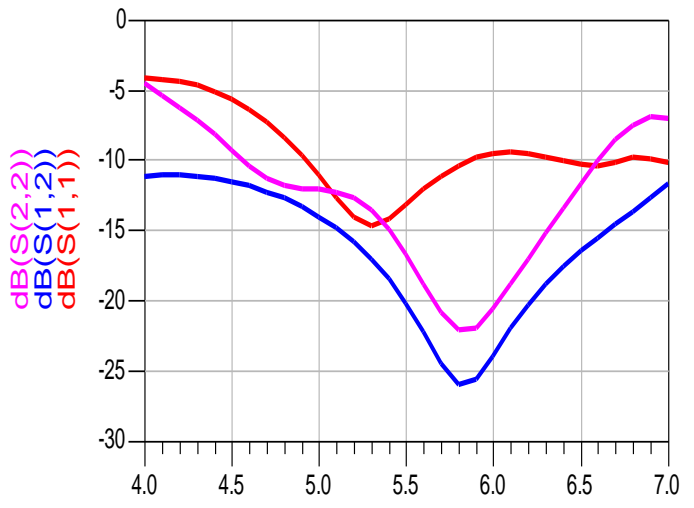

freq, $\mathrm{GHz}$

a)

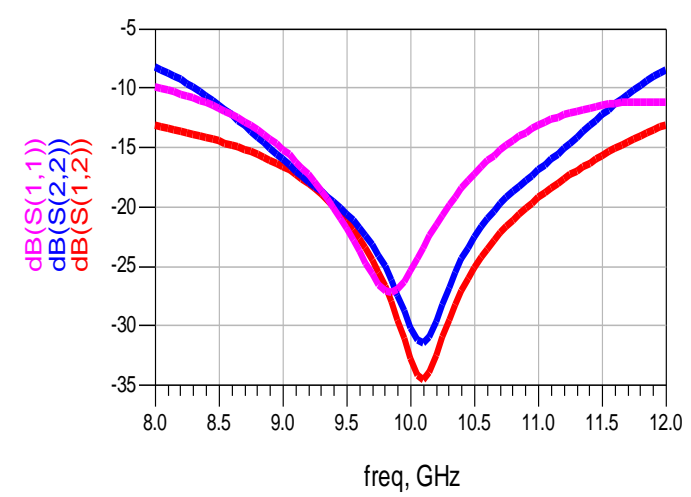

b)

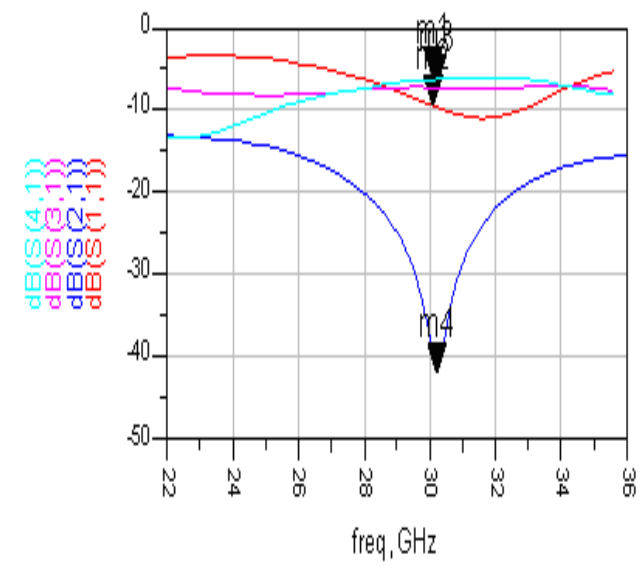

c)

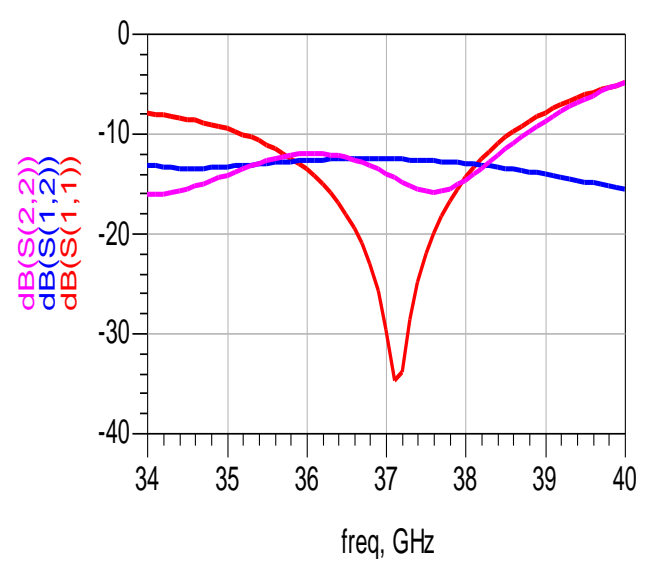

d)

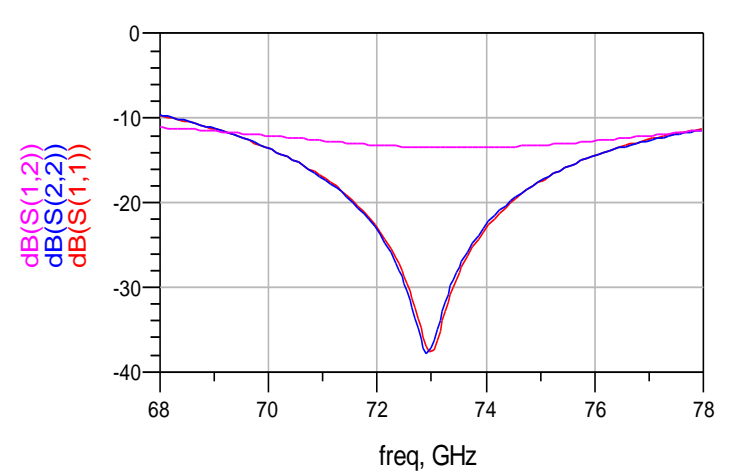

e)

Fig .5: Simulated results for S11, S22and $\mathrm{S12}$ for a) $5.8 \mathrm{GHz}$ b) $10 \mathrm{GHz}$ c) $30 \mathrm{GHz}$ d) $37 \mathrm{GHz}$ e) $73 \mathrm{GHz}$

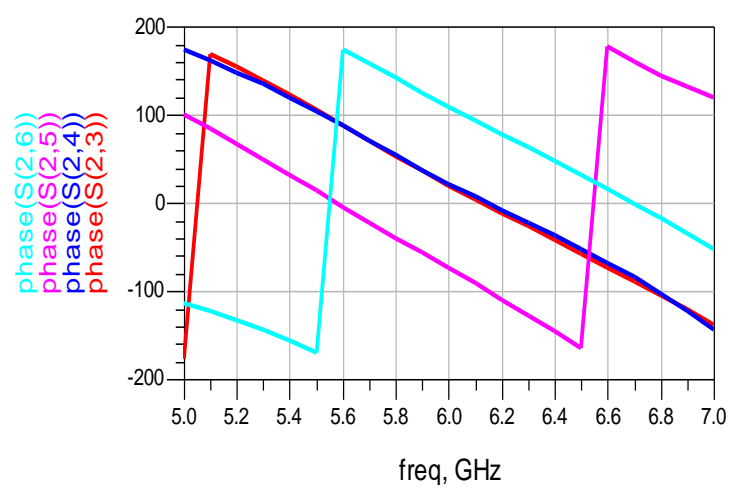

a) 


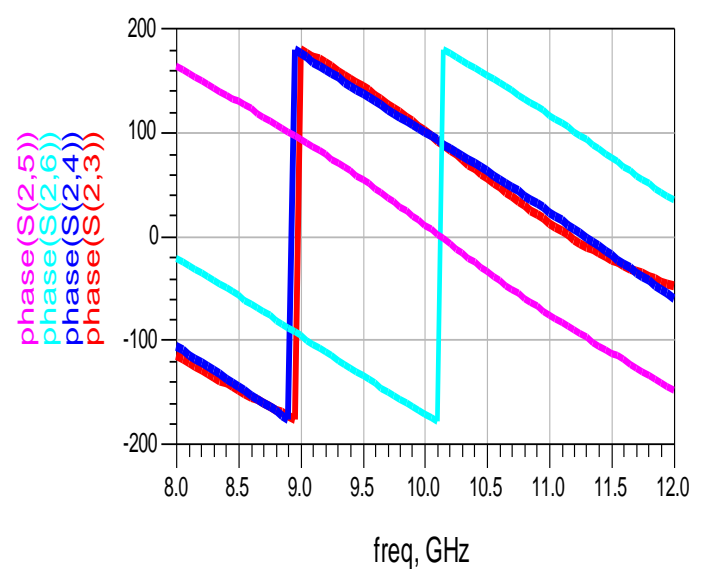

b)

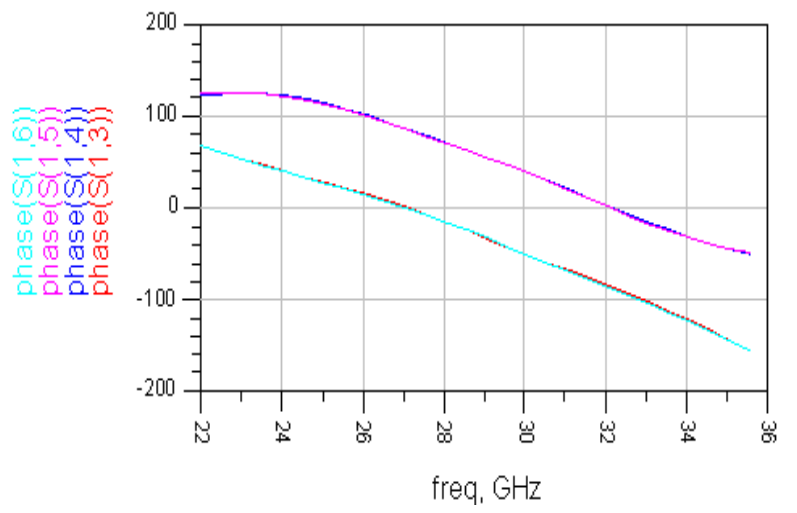

c)

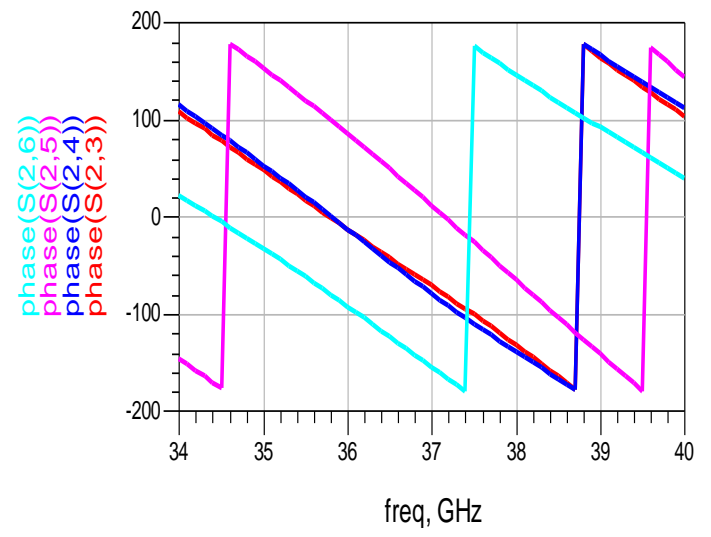

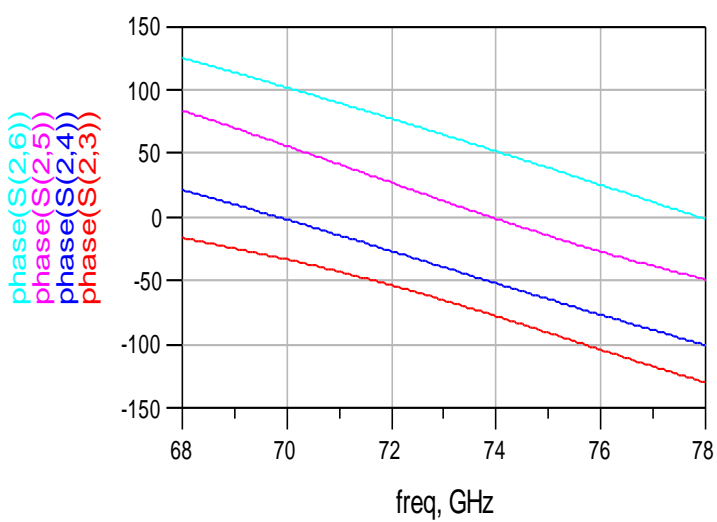

e)

Fig.6 : Simulated results of phase port 2 to output ports $S 13, S 14, S 15$ and $S 16$ for a) $5.8 \mathrm{GHz}$ b) $10 \mathrm{GHz}$ c) $30 \mathrm{GHz} \mathrm{d)} 37 \mathrm{GHz}$ e) $73 \mathrm{GHz}$

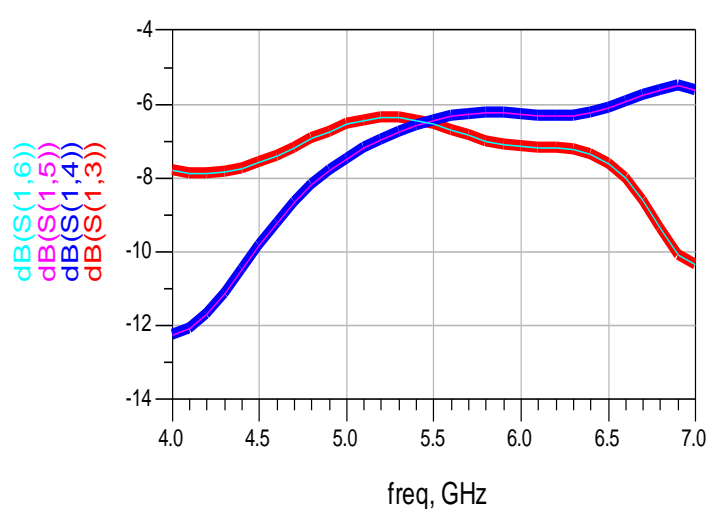

a)

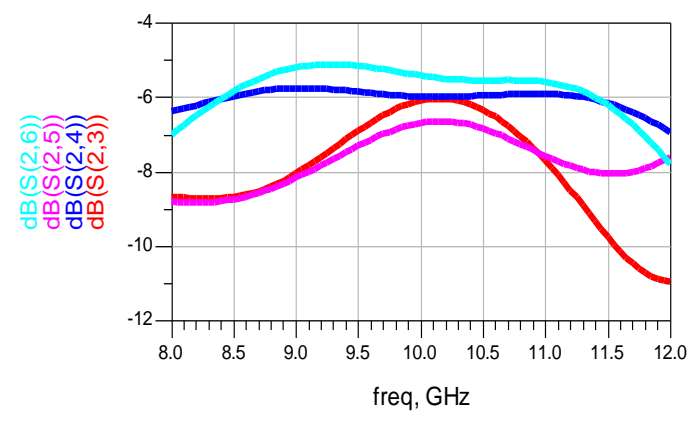




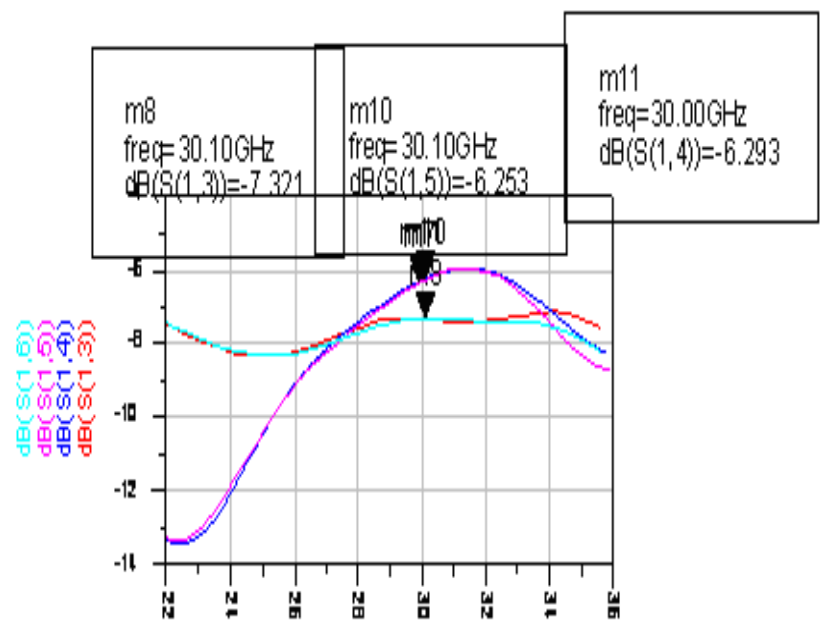

C)

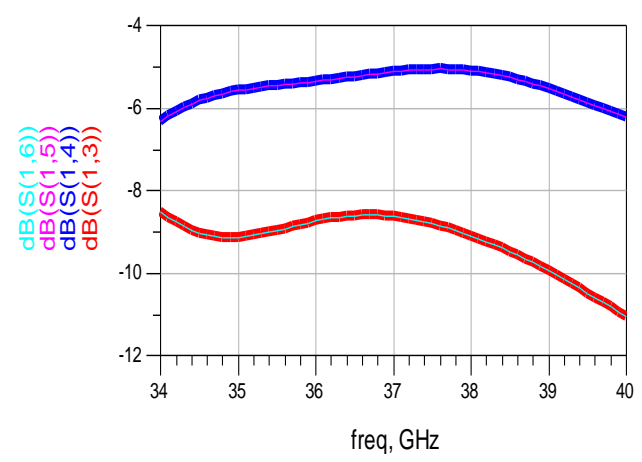

d)

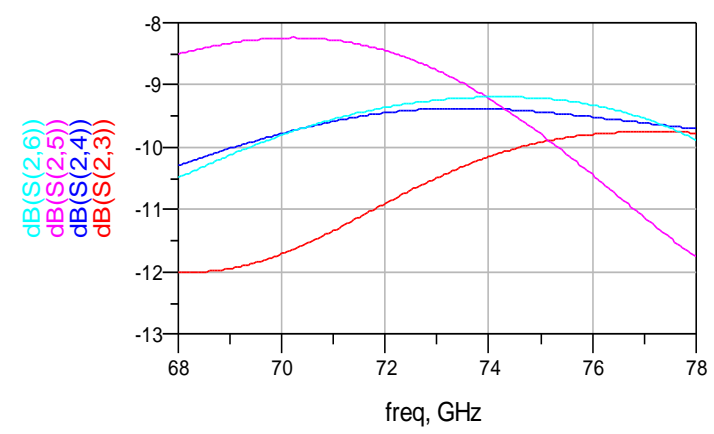

e)

Fig.7: Simulated results for S13, S14, S15 and $\mathrm{S} 16$ for a) $5.8 \mathrm{GHz}$ b) $10 \mathrm{GHz}$ c) $30 \mathrm{GHz}$ d) $37 \mathrm{GHz}$ e) $73 \mathrm{GHz}$

development cost, and a high potential for software reuse. The characteristics of six-ports for $5.8 \mathrm{GHz}$ and $37 \mathrm{GHz}$ are simulated using which means smaller energy loss of the whole circuit. Simulation results show that the Microstrip structure can achieve smaller insertion loss between the RF input port and output ports and more isolation between the RF input port and $\mathrm{LO}$ port.

\section{CONCLUSION}

The six-port junctions based on Micro-strip technology for cognitive radio has been proposed and presented. Combining the power divider and hybrid couplers, a six-port junction has been constructed. The whole design is simulated using Advanced Design System (ADS). The simulation results showing that the transmission coefficients for $5.8 \mathrm{GHz}$ and $10 \mathrm{GHz}$ are $-6 \mathrm{~dB}$ which is close to theoretical predicted value. But for $30 \mathrm{GHz}, 37 \mathrm{GHz}$ and $73 \mathrm{GHz}$ the transmission coefficient is $-8 \mathrm{~dB}$. Hence at higher frequencies which is greater than $10 \mathrm{GHz}$ the microstrip line has some losses.

\section{REFERENCES}

[1] X. T. Fang, X.-C. Zhang, and C.-M. Tong, "A novel miniaturized In Electromagnetics Research microstrip six-port junction," Progress In Electromagnetics Research Letters, Vol. 23, 129-135, 2011.

[2] Traii, M.; Nedil, M.; Gharsallah, A.; Denidni, T.A "Design of a six-port junction based on single layer technology for UWB applications", IEEE Electrical and Computer Engineering (CCECE), 2010 23rd Canadian Conference on 2010 pages $1-4$

[3] Han Song and shao-Bin Liu, Song Liu "A new six port junction based on microstrip technology" IEEE Trans 2009.

[4] Sebastian .M.Winter, Alexandra Koelpin, Robert Weigel, "Six port receiver analog front end;Multilayer Design and System," IEEE Trans,, vol.55, pp. 254-258, March 2008.

[5] J. Li, R.-G. Bosisio and K. Wu, "A six-port direct digital to-RF millimeter wave receiver," IEEE MTT Symposium Digest,, vol. 3, pp. 1659-1662, May 1995.

[6] S. O. Tatu, E. Moldovan, K. Wu, R. G. Bosisio, T. A. Denidni, "Ka-band analog front-end for software-defined direct conversion receiver," IEEE Trans. Microw. Theory Tech., vol. 53, no. 9, pp. 2768-2776, Sept. 2005.

[7] F. Gatti, M. Bozzi, L. Perregrini, K. Wu, and R. G. Bosisio, "A new wide-band six-port junction based on substrate integrated coaxial line (SICL) technology," IEEE Melecon Conf., pp. 367- 370, May. 2006.

[8] C. Carta, R. Vogt, W. Bachtold, "Multiband monolithic BICMOS low-power low-IF WLAN receivers," IEEE Microw. Wireless Compon. Lett., vol.15, No. 9, pp 543-545, Sept. 2005.

[9] S.-F. R. Chang, W.-L.Chen, S.-C. Chang, "A dual-band RF transceiver for multistandard WLAN applications," IEEE Trans. Microw. Theory Tech., vol. 53, no. 3, pp. 1048-1055, March. 2005.

[10] Djoumessi, E.E. ,Tatu, S.O. , Ke Wu "Frequency-Agile Dual-Band Direct Conversion Receiver for Cognitive Radio Systems" IEEE Trans ,vol. 58,pp.87-94. Jan 2010

[11] Djoumessi, E.E., Tatu, S.O., Ke Wu "Reconfigurable $\mathrm{RF}$ front-end for frequency-agile direct conversion receivers and cognitive radio system applications IEEE Trans ,pp.272-275. Jan 2010 


\section{AUTHORS PROFILE}

Siva sundara pandian.S is an $\begin{array}{lccr}\text { Engineering } & \text { Graduate in } & \text { Electronics } & \text { and } \\ \text { Communication } & \text { Engineering } & \text { from } & \text { Madurai }\end{array}$ Kamaraj University, (Tamilnadu), India. Did his Masters of Technology in VLSI design from Sathyabama University, Chennai (Tamilnadu). At present, he is pursuing PhD from Sathyabama University, Chennai (India). He has a total experience of 11 years which includes teaching as well as industrial. His research area is Microwave antennas and six port junctions for cognitive radio
Suriyakala.C.D is an Engineering Graduate in Electronics and Communication Engineering from Manipal Institute of Technology, Manipal. Did her Masters M.S.(By Research) from Anna University University, Chennai (Tamilnadu) \& PhD form Sathyabama University. At present, She is associated with Electronics \& Tele communication Engg. Department, Sathyabama University, Chennai (Tamilnadu). She has a total experience of 19 years which includes teaching as well as industrial .Her research area is in software Agents for Communication. 